\title{
NHỔI MÁU NÃO SAU CHẤN THƯƠNG ĐộNG MẠCH CẢNH - BÀN VỀ THÁI ĐỘ XỬ TRÍ MộT CA BỆNH
}

\section{TÓM TẮT}

Nhồi máu não là biến chứng khá thường gặp sau chấn thương động mạch cảnh. Mặc dù đã có những hướng dẫn điều trị chung, cách tiếp cận cũng như chiến lược điều trị trong nhiều trường hợp vẫn còn tranh cãi. Báo cáo bệnh nhân nam 33 tuổi, tai nạn cọc sắt đầm vào vùng III cổ trái. Sau tai nạn bệnh nhân tỉnh, được chẩn đoán chấn thương động mạch cảnh độ IV, huyết khối lan tới động mạch cảnh trong đoạn trong sọ. Không được sử dụng thuốc chống đông, bệnh nhân xuất hiện nhồi máu não, hôn mê sau tai nạn 7 giờ. Người bệnh được mổ tái thông động mạch cảnh trong và lấy huyết khối. MRI sọ não sau mổ thấy tắc hoàn toàn động mạch não giữa và nhồi máu não diện rộng. Người bệnh ra viện với di chứng liệt nửa người. Mục đích của bài báo nhằm phân tích vai trò của điều trị chống đông và tính khả thi của chiến lược điều trị phối hợp giữa phẫu thuật và can thiệp nội mạch ở bệnh nhân chấn thương động mạch cảnh độ IV có huyết khối lan vào động mạch trong sọ.

Tù khóa: nhồi máu não sau chấn thuoong động mạch cảnh, chấn thương động mạch cảnh.

\section{I. ĐẶT VẤN ĐỀ}

Chấn thương động mạch cảnh cho đến nay vẫn được báo cáo chiếm tỷ lệ thấp, $1-2 \%$ chấn thương chung, $9 \%$ chấn thương nặng ở đầu, cổ[1]. Theo Denver, chấn thương động mạch cảnh được chia thành 5 cấp độ; trong đó chấn thương độ IV (tắc hoàn toàn động mạch cảnh) hay được ghi nhận trên lâm sàng với tỉ lệ biến chứng nhồi máu não khá cao, khoảng $10-40 \%$ [2]. Theo Berlew cùng cộng sự, nhồi máu não xuất hiện muộn trong vòng 72 giờ sau tai nạn chiếm tỉ lệ 61\%[3]. Vì vậy, dự phòng nhồi máu
Đặng Quang Huy ${ }^{*}$, Hán Văn Hòa**

não sau chấn thương động mạch cảnh bằng thuốc chống đông đã được khuyến cáo trong nhiều hướng dẫn điều trị $[4,5]$. Mặc dù phưng pháp phối hợp phẫu thuật và can thiệp nội mạch đã được nhắc đến trong một số báo cáo, chưa có hướng dẫn áp dụng trong những trường hợp cụ thể $[6,7]$. Dưới đây là ca chấn thương động mạch cảnh độ IV; mặc dù được chẩn đoán sớm nhưng chiến lược điều trị chưa phù hợp khiến bệnh nhân phải chịu di chứng thần kinh sau mổ.

\section{BÁO CÁO CA BỆNH}

Nam bệnh nhân 33 tuổi, tai nạn cọc sắt đâm vào vùng III cổ trái. Sau tai nạn, tri giác bệnh nhân 15 điểm, CTscanner sọ não bình thường, chụp cắt lớp động mạch cho hình ảnh tắc hoàn toàn động mạch cảnh trong và ngoài trái sau vị trí chia $4 \mathrm{~cm}$ lan đến nền sọ. Sau chẩn đoán, bệnh nhân vẫn không được sử dụng kháng đông và kháng tiểu cầu. Triệu chứng đột quỵ xuất hiện 7 giờ sau tai nạn,bệnh nhân hôn mê, liệt nửa người phải, Glasgow 9 điểm. Phẫu thuật cắt một phần đụng dập động mạch cảnh trong đến sát nền sọ, lấy huyết khối bằng forgety số 3 và 2 . Dòng trào ngược yếu, nối trực tiếp 2 đầu mạch. Sau mổ,bệnh nhân không được dùng kháng đông 6 giờ, MRI sọ não thấy tắc hoàn toàn động mạch não giữa trái và các nhánh trong não, nhồi máu não trái. Duy trì kháng tiểu cầu sau mổ, ra viện sau 7 ngày, bệnh nhân tỉnh, liệt nửa người phải.

\footnotetext{
* Bệnh viện tim Hà Nội

** Bệnh viện đa khoa tỉnh Phú Tho Ngưòi chịu trách nhiệm khoa học: Bs Hán Văn Hòa Ngày nhận bài: 01/11/2019 - Ngày Cho Phép Đăng: 20/12/2019 Phản Biện Khoa học: PGS.TS. Đặng Ngọc Hùng GS.TS. Lê Ngoc Thành
} 


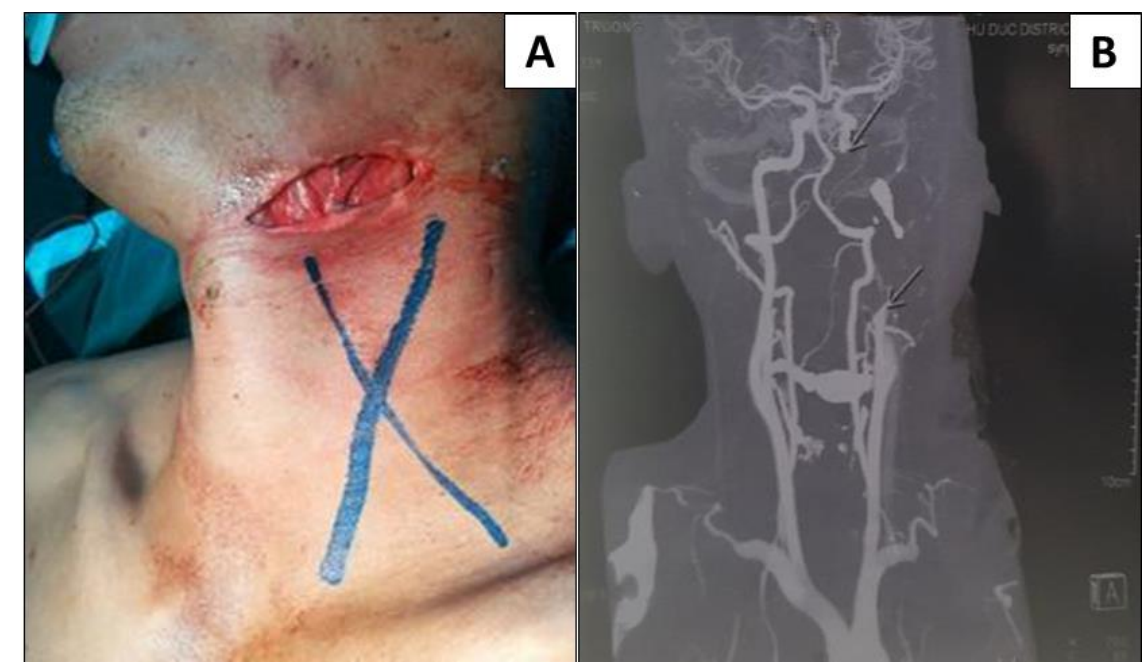

Hình 1: Thuoong tổn của bệnh nhân trước mổ

$\mathbf{A}$, vết thương ngoài da kèm theo đụng dập, tụ máu vùng III cổ trái; $\mathbf{B}$, phim chụp cắt lớp động mạch cảnh và các động mạch trong sọ, dựng hình xóa nền. Động mạch cảnh trong bị tổn thương mất đoạn trên một đoạn dài, bắt đầu từ sau chỗ chia động mạch cảnh trong - cảnh ngoài khoảng $2 \mathrm{~cm}$ đến hết đoạn trong xương đá của động mạch cảnh trong (mũi tên).

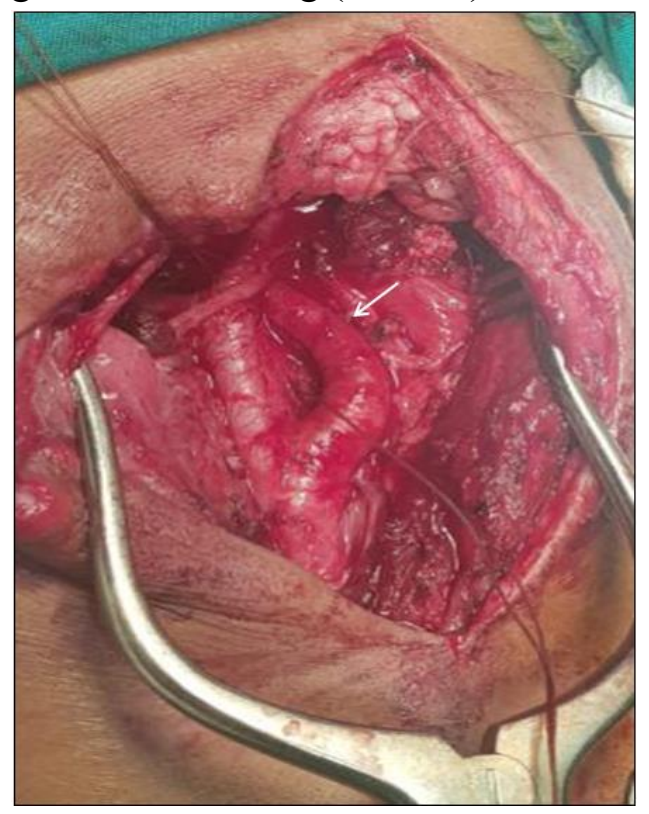

Hình 2: Hình ảnh tổn thương trong mổ

Động mạch cảnh trong bị đụng dập và bị lấp đầy bởi huyết khối (mũi tên) từ sau chỗ chia động mạch cảnh trong, cảnh ngoài khoảng $2 \mathrm{~cm}$.

\section{BÀN LUẬN}

Khác với vết thương, trong chấn thương động mạch cảnh, thành động mạch bị đụng dập gây nhiều dạng tổn thương khác nhau, bao gồm:
(1) máu tụ trong thành dẫn tới hẹp lòng mạch, (2) rách lớp nội mạc gây lóc động mạch, (3) thành động mạch bị rách một phần tạo thành túi giả phình, (4) đụng dập gây gián đoạn một phần 
mạch máu, và (5) đứt rời động mạch chảy máu ra tổ chức xung quanh. Các hình thức tổn thương giải phẫu đó tương ứng với 5 mức độ trong phân loại của Denver[4, 5]. Có ba cơ chế gây nhồi máu não ở bệnh nhân bị chấn thương động mạch cảnh, bao gồm: (1) tắc hoàn toàn động mạch cảnh trong một bên ở bệnh nhân có vòng nối đa giác Willis không đầy đủ, (2) huyết khối trôi lên gây tắc các động mạch não, và (3) huyết khối từ động mạch cảnh bị đụng dập lan lên gây tắc các động mạch não. Đó là lý do giải thích thực tế nhồi máu não có thể xuất hiện ngay sau vài phút hoặc xuật hiện muộn đến 72 giờ sau chấn thương [8]. Chúng ta có thể tạm gọi ra thành 2 nhóm cơ chế nhồi máu não: cơ chế tiên phát (cơ chế đầu tiên) và nhóm cơ chế thứ phát ( 2 cơ chế sau do huyết khối lan lên hoặc trôi đi). Để phòng cơ chế nhồi máu não thứ phát, hầu hết hướng dẫn điều trị đều khuyến cáo sử dụng thuốc chống đông ngay khi xác định chẩn đoán và loại trừ nguy cơ chảy máu $[4,9]$. Tso cùng cộng sự thậm chí còn cho rằng có thể sử dụng thuốc chống đông ngay cả ở những bệnh nhân có chân thương sọ não kèm theo [10].

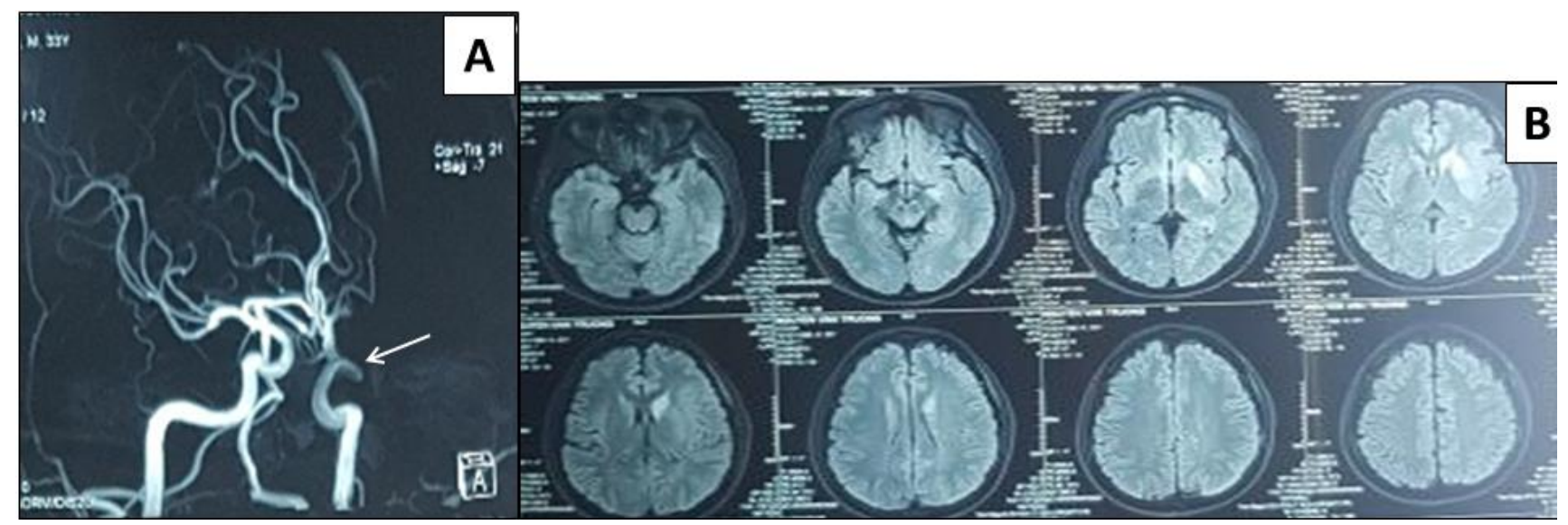

Hình 3: Hình ảnh tổn thưong sau mổ

A, phim chụp cắt lớp động mạch trong sọ, dựng hình, xóa nền. Động mạch cảnh trong đoạn trong xương đá (mũi tên) và nhánh của động mạch não giữa bị tắc bởi huyết khối. $\mathbf{B}$, hình ảnh nhồi máu não vùng vỏ thùy thái dương bên trái trên phim chụp cộng hưởng từ sọ não

Trong báo cáo của chúng tôi, bệnh nhân được chẩn đoán sớm khi chưa có biến cố thần kinh, chấn thương động mạch cảnh trong độ IV với huyết khối đã lan vào trong sọ tới sát đa giác Willis. Ở bệnh nhân có nguy cơ nhồi máu não cao như bệnh nhân này, việc sử dụng thuốc chống đông là thực sự cần thiết để phòng cơ chế nhồi máu não thứ phát. Mặc dù vậy, bệnh nhân đã không được chỉ định thuốc chống đông, kết quả dẫn tới nhồi máu não xuất hiện sau chấn thương 7 giờ.
Với chấn thương hoặc vết thương cổ vùng III, chấn thương động mạch cảnh độ IV có chỉ định phẫu thuật tái thông mạch trong tất cả các trường hợp, ngoại trừ: chấn thương động mạch cảnh trong đoạn trong xương đá (vỡ nền sọ kèm theo), thể trạng bệnh nhân rất yếu không chịu được cuộc phẫu thuật, hôn mê sâu do thiếu máu não muộn hoặc chấn thương sọ não nặng kèm theo... [5]. Mặc dù vậy, chưa có hướng dẫn điều trị trong trường hợp chấn thương đông mạch cảnh độ IV có huyết khối lan sâu vào động mạch cảnh trong đoạn trong xương đá. Bệnh nhân của chúng tôi có đoạn đụng dập mạch nằm khu trú cách chỗ chia động mạch cảnh trong và cảnh ngoài $2 \mathrm{~cm}$. Tình trạng nguyên vẹn của xương nền sọ được xác định bằng phim chụp cắt lớp đa dẫy giúp 
khẳng định phần động mạch cảnh trong đoạn trong xương đá không ngấm thuốc trên phim chụp mạch là huyết khối thay vì ổ đụng dập do chấn thương. Trong những trường hợp này, phẫu thuật cần giải quyết 2 vấn đề: cắt bỏ đoạn mạch bị đụng dập và lấy được hết huyết khối ở động mạch cảnh trong đoạn trong sọ. Fogarty gần như không có khả năng lấy được huyết khối ở phần trong xương đá của động mạch cảnh trong do đường đi của động mạch có nhiều đoạn uốn khúc.

Bệnh nhân của chúng tôi khi xuất hiện biến cố thần kinh, chỉ định phẫu thuật ngay là hợp lý. Mặc dù vậy, phẫu thuật cắt nối động mạch cảnh như thường quy không thể lấy được huyết khối gây tắc các động mạch não - là nguyên nhân gây biểu hiện đột quỵ trên lâm sàng. Can thiệp nội mạch là phương pháp hiệu quả nhất trong việc lấy bỏ huyết khối ở động mạch cảnh trong đoạn xương đá và các động mạch não.Chúng tôi đề xuất một cách tiếp cận phối hợp (hybrid), trong đó phẫu thuật được thực hiện trước để tái thông lại vị trí động mạch cảnh bị đụng dập; sau đó can thiệp nội mạch được thực hiện ngay với đường vào từ động mạch cảnh để lấy bỏ huyết khối gây tắc động mạch cảnh trong đoạn xương đá và các động mạch não.Trong nghiên cứu của $\mathrm{Li}$ cùng cộng sự, có 3 trường hợp chấn thương động mạch cảnh được điều trị bằng phương pháp phối hợp phẫu thuật và can thiệp nội mạch. Tuy nhiên cả 3 trường hợp này không được mô tả chi tiết về thương tổn và hiệu quả điều trị[[6]. Về lý thuyết phương pháp hybrid có tính khả thi mặc dù vậy chúng ta cần thêm nhiều báo cáo lâm sàng hơn nữa để đánh giá hiệu quả của phương pháp.

\section{KẾT LUẬN}

Thuốc chống đông đóng vai trò quan trọng trong phòng ngừa biến chứng nhồi máu não xuất hiện muộn ở bệnh nhân chấn thương động mạch cảnh. Phẫu thuật hối hợp với can thiệp nội mạch có thể có hiệu quả trong những trường hợp huyết khối lan vào động mạch trong sọ. Mặc dù vậy, phương pháp này cần thêm thời gian để chứng minh tính hiệu quả.

\section{TÀI LIẸU THAM KHẢO}

1. Brommeland T, Helseth E, Aarhus M, Moen KG, Dyrskog S, Bergholt B, et al. Best practice guidelines for blunt cerebrovascular injury (BCVI). Scandinavian journal of trauma, resuscitation and emergency medicine. 2018;26(1):90.

2. Stone DK, Viswanathan VT, Wilson CA. Management of Blunt Cerebrovascular Injury. Current neurology and neuroscience reports. 2018;18(12):98.

3. Burlew CC, Sumislawski JJ, Behnfield CD, McNutt MK, McCarthy J, Sharpe JP, et al. Time to stroke: A Western Trauma Association multicenter study of blunt cerebrovascular injuries. The journal of trauma and acute care surgery. 2018 Nov;85(5):858-66. PubMed PMID: 29847537. Epub 2018/05/31. eng.

4. Brommeland T, Helseth E, Aarhus M, Moen KG, Dyrskog S, Bergholt B, et al. Best practice guidelines for blunt cerebrovascular injury (BCVI). Scandinavian journal of trauma, resuscitation and emergency medicine. 2018 Oct 29;26(1):90. PubMed PMID: 30373641. Pubmed Central PMCID: PMC6206718. Epub 2018/10/31. eng.

5. Bromberg WJ, Collier BC, Diebel LN, Dwyer KM, Holevar MR, Jacobs DG, et al. Blunt cerebrovascular injury practice management guidelines: the Eastern Association for the Surgery of Trauma. The Journal of trauma. 2010 Feb;68(2):471-7. PubMed PMID: 20154559. Epub 2010/02/16. eng.

6. Li W, D'Ayala M, Hirshberg A, Briggs W, Wise L, Tortolani A. Comparison of conservative and operative treatment for blunt carotid injuries: analysis of the National Trauma Data Bank. Journal of vascular surgery. 2010 Mar;51(3):593-9, 9 e1-2. PubMed PMID: 20206804. Epub 2010/03/09. eng. 
7. Blitzer DN, Ottochian M, O'Connor JV, Feliciano DV, Morrison JJ, DuBose JJ, et al. Timing of intervention may influence outcomes in blunt injury to the carotid artery. Journal of vascular surgery. 2019 Sep 9. PubMed PMID: 31515175. Epub 2019/09/14. eng.

8. Burlew CC, Biffl WL, Moore EE, Pieracci FM, Beauchamp KM, Stovall R, et al. Endovascular stenting is rarely necessary for the management of blunt cerebrovascular injuries. Journal of the American College of Surgeons. 2014 May;218(5):1012-7. PubMed PMID: 24661857. Epub 2014/03/26. eng.
9. Grigorian A, Kabutey NK, Schubl S, de Virgilio C, Joe V, Dolich $\mathrm{M}$, et al. Blunt cerebrovascular injury incidence, stroke-rate, and mortality with the expanded Denver criteria. Surgery. 2018 Sep;164(3):494-9. PubMed PMID: 29884478. Epub 2018/06/10. eng.

10. Tso MK, Lee MM, Ball CG, Morrish WF, Mitha AP, Kirkpatrick AW, et al. Clinical utility of a screening protocol for blunt cerebrovascular injury using computed tomography angiography. Journal of neurosurgery. 2017 Apr;126(4):1033-41. PubMed PMID: 27104846. Epub 2016/04/23. eng. 